\title{
A Fault Finding Analysis of Transformer Internal Defects
}

\author{
Dai Yini ${ }^{1}$, Liu Jiani ${ }^{3}$, Jin Haipeng ${ }^{1}$ Xu Hao ${ }^{1}$, Liu Nan ${ }^{1}$, Wang Wenjing ${ }^{1}$, Wang Yuting ${ }^{1}$, \\ Zhang Zhao ${ }^{2}$, Zhu $\mathrm{Bo}^{2}$, Qu $\mathbf{Y i}^{2}$ \\ ${ }^{1}$ State grid Fuxin electric power supply company \\ ${ }^{2}$ State grid Fushun electric power supply company \\ ${ }^{3}$ Measuring center, Liaoning electric power company limited, state grid, China
}

Keywords: transformer, lead wire diversion, Insulation oil, chromatographic analysis

\begin{abstract}
Transformer is the main equipment, whose stable and reliable operation play an important role in the state grid. The process and method of finding overheating faults are illustrated through the case of a $66 \mathrm{kV}$ transformer internal fault. At the same time, it is verified that the gas chromatographic analysis is important for the detection of transformer defects in combination with electrical test methods such as insulation resistance, DC resistance tester, transformation ratio, dielectric loss, and capacitance.
\end{abstract}

\section{Introduction}

Power transformer that has a significant influence on the safety of the power grid so much is an important device for converting voltage and transmitting electrical energy in power system. If it is not handled in time that abnormal phenomenon of transformer appear during operation, the transformer may suffer serious failure, even more can be burned down, which will directly affect the normal operation of the entire power system, resulting in economic losses and even negative social impact.

According to the statistical analysis of previous data, the causes of damaging transformer interior are mainly divided into two categories: superheat fault and discharge fault. The magnetic circuit or the conductive circuit is a common part that is considered to cause transformer overheating faults. The reasons that make transformer overheat can be composed by overheating of the winding, poor contacting of tap-changer, overheating of lead wire diversion, overheating of lead wire connector, multipoint grounding of the iron, magnetic flux leakage leading to overheating, cooling device's fault, partial overheating due to foreign matter and so on. The cause of transformer discharge faults are consisted of partial discharge, spark discharge, electric arc discharge and so on.

\section{Cases}

When a $20000 \mathrm{kVA}$ transformer in a $66 \mathrm{kV}$ substation is subjected to periodic transformer oil gas chromatographic analysis, the standard value required by the procedure is far exceeded because of the abnormality of the characteristic gas components found in the oil. The data on the gas content of the transformer in the near future is shown in Table 1:

Table 1 The data of gas content

\begin{tabular}{|c|c|c|c|c|c|c|c|c|c|}
\hline \multirow[b]{2}{*}{ No. } & \multirow{2}{*}{$\begin{array}{l}\text { Date of } \\
\text { testing }\end{array}$} & \multicolumn{8}{|c|}{ Gas composition $(\mu \mathrm{L} / \mathrm{L})$} \\
\hline & & $\mathrm{CH}_{4}$ & $\mathrm{C}_{2} \mathrm{H}_{4}$ & $\mathrm{C}_{2} \mathrm{H}_{6}$ & $\mathrm{C}_{2} \mathrm{H}_{2}$ & $\mathrm{H}_{2}$ & $\mathrm{CO}$ & $\mathrm{CO}_{2}$ & $\begin{array}{l}\text { Total } \\
\text { hydrocarbon }\end{array}$ \\
\hline 1 & 2015.11.29 & 22.23 & 20.8 & 12.96 & 0.14 & 1.70 & 433.19 & 3115.11 & 56.12 \\
\hline 2 & 2016.12.19 & 317.87 & 1074.18 & 194.5 & 28.38 & 105.15 & 1032.8 & 5166.48 & 1614.93 \\
\hline
\end{tabular}




\section{Finding fault location}

\subsection{Finding fault cause}

According to the transformer insulation oil gas chromatographic analysis data, large amounts of $\mathrm{CH}_{4}$ and $\mathrm{C}_{2} \mathrm{H}_{4}$ are contained in the oil. It is very likely that there is an overheating fault in the interior. Or there may be a discharge failure in result of the $\mathrm{C}_{2} \mathrm{H}_{2}$ content reaching $28.38 \mu \mathrm{L} / \mathrm{L}$. Meanwhile the $\mathrm{CO}$ and $\mathrm{CO}_{2}$ content is also high, so solid insulation may be involved in the fault. Next, the three ratio method and four ratio method are used to further determine the property and location of the fault.

\subsubsection{Judging the property of the fault by the three ratio method}

Table 2 The rules of The three-ratio encoding method

\begin{tabular}{c|c|c|c}
\hline \multirow{2}{*}{ The ratio of characteristic gas } & \multicolumn{3}{|c}{ Ratio range coding } \\
\cline { 2 - 4 } & $\mathrm{C}_{2} \mathrm{H}_{2} / \mathrm{C}_{2} \mathrm{H}_{4}$ & $\mathrm{CH}_{4} / \mathrm{H}_{2}$ & $\mathrm{C}_{2} \mathrm{H}_{4} / \mathrm{C}_{2} \mathrm{H}_{6}$ \\
\hline$<0.1$ & 0 & 1 & 0 \\
\hline$\geq 0.1 \sim<1$ & 1 & 0 & 0 \\
\hline$\geq 1 \sim<3$ & 1 & 2 & 2 \\
\hline$\geq 3$ & 2 & 2 & 1 \\
\hline
\end{tabular}

According to the coding rule of the three-ratio method, a set of ratios of the characteristic gas components that are included in transformer body insulation oil in 2016 is calculated. As shown in table 3:

Table 3 Three-ratio method results

\begin{tabular}{c|c|c|c}
\hline \multirow{2}{*}{ Date of testing } & \multicolumn{3}{|c}{ ratio } \\
\cline { 2 - 4 } & $\mathrm{C}_{2} \mathrm{H}_{2} / \mathrm{C}_{2} \mathrm{H}_{4}$ & $\mathrm{CH}_{4} / \mathrm{H}_{2}$ & $\mathrm{C}_{2} \mathrm{H}_{4} / \mathrm{C}_{2} \mathrm{H}_{6}$ \\
\hline 2016.12 .19 & 0.026 & 3.02 & 5.52 \\
\hline
\end{tabular}

According to the coding rule of the three-ratio method, the coding combination of a group of test data in the table is " $0,2,2$ ". Chromatographic analysis is the same. Based on the procedural standards, the corresponding fault type is determined as high temperature overheating. It is a discharge phenomenon on account of that $\mathrm{C}_{2} \mathrm{H}_{2}$ content is $28.38 \mu \mathrm{L} / \mathrm{L}$. Therefore, it is initially determined that the fault is a high-temperature over-temperature and discharge fault.

\subsubsection{Determining the fault location by the four-ratio method}

In the four-ratio method, the fault location is on magnetic circuit when the four characteristic gases of $\mathrm{CH}_{4}, \mathrm{C}_{2} \mathrm{H}_{4}, \mathrm{C}_{2} \mathrm{H}_{6}, \mathrm{C}_{2} \mathrm{H}_{2}$, and $\mathrm{H}_{2}$ are simultaneously satisfied with the four conditions of $\mathrm{CH}_{4} / \mathrm{H}_{2}=1 \sim 3, \mathrm{C}_{2} \mathrm{H}_{6} / \mathrm{CH}_{4}<1, \mathrm{C}_{2} \mathrm{H}_{4} / \mathrm{C}_{2} \mathrm{H}_{6} \geq 3$, and $\mathrm{C}_{2} \mathrm{H}_{2} / \mathrm{C}_{2} \mathrm{H}_{4}<0.5$, otherwise on conductive circuit. $\mathrm{CH}_{4} / \mathrm{H}_{2}=3.02$ by calculation, which is not in the range of $1 \sim 3$, the fault location is determined on the conductive circuit. In addition, transformer is tested that iron ground current value is less than $100 \mathrm{~mA}$, insulation resistance is greater than $1000 \mathrm{M} \Omega$.Excluding the multi-point grounding fault of the iron is consistent with the judgment result of the four-ratio method.

\subsection{Locating the fault location}

Combined with the gas chromatographic analysis, there are four main reasons why transformer fault may exist: (1)poor contacting of tap-changer; (2)loose bolt of lead wire clips or poor welding of linker and short circuit in windings; (3)the fault of lead wire diversion; (4)short circuit in windings, broken strands, poor insulation between layers.

The third day after the transformer gas chromatographic analysis exceeded the data, the transformer was subjected to power cut and four electrical tests in insulation resistance, DC resistor, transformation ratio, dielectric loss, and capacitance. Transformer insulation resistance test data is shown in table 4: 
Table 4 Transformer Insulation Resistance test report

\begin{tabular}{|c|c|c|c|c|c|}
\hline \multirow{2}{*}{$\begin{array}{l}\text { Measurement } \\
\text { site }\end{array}$} & \multicolumn{3}{|c|}{ Trial value(M $(\mathrm{M}) /$ Oil temperature $20^{\circ} \mathrm{C}$} & \multirow{2}{*}{$\begin{array}{l}\text { Absorption } \\
\text { ratio }\end{array}$} & \multirow{2}{*}{$\begin{array}{l}\text { Polarization } \\
\text { index }\end{array}$} \\
\hline & R15S & R60S & R600S & & \\
\hline $\begin{array}{l}\text { high-voltage to } \\
\text { low-voltage with } \\
\text { ground }\end{array}$ & 141000 & 184000 & & 1.30 & \\
\hline $\begin{array}{l}\text { low -voltage to } \\
\text { high -voltage } \\
\text { with ground }\end{array}$ & 64900 & 77400 & & 1.04 & \\
\hline Conclusion & $\begin{array}{l}\text { According } \\
\text { insulation } \\
\text { value at the } \\
\text { not less thar } \\
\text { comparison. }\end{array}$ & $\begin{array}{l}\text { vant stan } \\
\text { of the tra } \\
\text { perature, } \\
\text { insulati }\end{array}$ & $\begin{array}{l}\text { test is q } \\
\text { s not lov } \\
\text { sorption } \\
\text { ce is gre }\end{array}$ & $\begin{array}{l}\text { d that the } \\
\text { in } 70 \% \text { of the } \\
\text { s not less tha } \\
\text { an } 10000 \mathrm{M} S\end{array}$ & $\begin{array}{l}1.3 \text { or PI is } \\
\text { oy }\end{array}$ \\
\hline
\end{tabular}

Transformer DC resistance data is tested as shown in table 5:

Table 5 Transformer DC resistance test report

\begin{tabular}{|c|c|c|c|c|}
\hline \multirow{2}{*}{ Tap position } & \multicolumn{3}{|c|}{ Trial value(M $\Omega) /$ Oil temperature $20^{\circ} \mathrm{C}$} & \multirow{2}{*}{$\begin{array}{l}\text { Non-balance } \\
\text { ratio }\end{array}$} \\
\hline & $\mathrm{OA}$ & OB & $\mathrm{OC}$ & \\
\hline 1 & 0.4517 & 0.4459 & 0.4454 & 1.44 \\
\hline 2 & 0.4463 & 0.4410 & 0.4408 & 1.25 \\
\hline 3 & 0.4412 & 0.4364 & 0.4357 & 1.26 \\
\hline 4 & 0.4376 & 0.4298 & 0.4306 & 1.81 \\
\hline 5 & 0.4321 & 0.4249 & 0.4250 & 1.69 \\
\hline 6 & 0.4253 & 0.4192 & 0.4196 & 1.45 \\
\hline 7 & 0.4196 & 0.4141 & 0.4142 & 1.38 \\
\hline 8 & 0.4165 & 0.4090 & 0.4101 & 1.82 \\
\hline 9 & 0.4092 & 0.4025 & 0.4016 & 1.86 \\
\hline 10 & 0.4148 & 0.4090 & 0.4093 & 1.43 \\
\hline 11 & 0.4203 & 0.4153 & 0.4145 & 1.41 \\
\hline 12 & 0.4253 & 0.4195 & 0.4198 & 1.36 \\
\hline 13 & 0.4320 & 0.4250 & 0.4249 & 1.66 \\
\hline 14 & 0.4356 & 0.4299 & 0.4299 & 1.33 \\
\hline 15 & 0.4406 & 0.4352 & 0.4357 & 1.26 \\
\hline 16 & 0.4477 & 0.4421 & 0.4415 & 1.40 \\
\hline 17 & 0.4522 & 0.4465 & 0.4459 & 1.41 \\
\hline Conclusion & \multicolumn{4}{|c|}{$\begin{array}{l}\text { The test is qualified that the difference among the resistors of each phase } \\
\text { winding should not exceed } 2 \% \text { of the three-phase DC resistor average in terms } \\
\text { of the regulations for transformers above 1600kVA. }\end{array}$} \\
\hline
\end{tabular}

$\operatorname{Tg} \delta$ and capacitance of transformer winding with casing are tested as shown in table 6 :

Table 6 Test report of tg $\delta$ and capacitance of transformer winding with casing

\begin{tabular}{|c|c|c|}
\hline \multirow{2}{*}{ Measurement site } & \multicolumn{2}{|c|}{ Trial value(M $\Omega$ ) /Oil temperature $20^{\circ} \mathrm{C}$} \\
\hline & $\mathrm{C} 0(\mathrm{nF})$ & $\operatorname{tg} \delta(\%)$ \\
\hline $\begin{array}{l}\text { high-voltage to } \\
\text { low-voltage with } \\
\text { ground }\end{array}$ & 6198 & 0.308 \\
\hline $\begin{array}{l}\text { low -voltage to high } \\
\text {-voltage with ground }\end{array}$ & 9435 & 0.315 \\
\hline Conclusion & \multicolumn{2}{|c|}{$\begin{array}{l}\text { The test is qualified that The deviation between the transformer capacity and } \\
\text { the factory value is less than } 3 \% \text {, meanwhile tg } \delta \text { is not more than } 0.8 \%\left(20^{\circ} \mathrm{C} \text {, }\right. \\
66 \mathrm{kV} \sim 220 \mathrm{kV}) \text { or } 0.6 \%\left(20^{\circ} \mathrm{C}, 500 \mathrm{kV}\right) \text { and is not more than } 130 \% \text { of the } \\
\text { factory temperature at the same temperature by comparison. }\end{array}$} \\
\hline
\end{tabular}


Transformer ratio data is tested as shown in table 7:

Table 7 Transformer ratio test report

\begin{tabular}{c|c|c|c}
\hline tap-changer & $\mathrm{AB} / \mathrm{ab}$ & $\mathrm{BC} / \mathrm{bc}$ & $\mathrm{CA} / \mathrm{ca}$ \\
\hline 1 & -0.11 & -0.11 & -0.13 \\
\hline 2 & 0.05 & 0.06 & 0.04 \\
\hline 3 & -0.08 & -0.07 & -0.10 \\
\hline 4 & 0.08 & 0.09 & 0.06 \\
\hline 5 & -0.05 & -0.04 & -0.07 \\
\hline 6 & 0.11 & 0.12 & 0.09 \\
\hline 7 & -0.01 & -0.00 & -0.03 \\
\hline 8 & -0.10 & -0.10 & -0.12 \\
\hline 9 & 0.05 & 0.05 & 0.03 \\
\hline 10 & -0.05 & -0.04 & -0.06 \\
\hline 11 & 0.08 & 0.09 & 0.06 \\
\hline 12 & -0.01 & -0.01 & -0.03 \\
\hline 13 & 0.12 & 0.12 & 0.12 \\
\hline 14 & 0.02 & 0.03 & 0.00 \\
\hline 15 & -0.10 & -0.08 & -0.11 \\
\hline 16 & 0.06 & 0.06 & 0.04 \\
\hline 17 & -0.04 & -0.04 & -0.07 \\
\hline Conclusion & According to the relevant standards, the test is qualified by comparison. \\
\hline
\end{tabular}

According to the above test data analysis: The traditional test items of the transformer meet the requirements of the regulations and have not grown significantly, such as the dielectric loss and capacitance of the transformer. The tap-changer in poor contact, loose bolts of lead clips or linker are badly welded, short circuit between winding turns, broken strands, and poor insulation between layers are ruled out as a result of overheating. Lead wire diversion was judged to be the cause of the transformer overheating through combining the results of gas chromatographic analysis in oil.

\section{Core inspection}

The core inspection was performed on the transformer after confirming the fault location. C phase lead cable of the transformer high-voltage side was found to have obvious signs of overheating and discharge due to contact with the root of the inner wall of the copper pipe of the high voltage casing, external insulation damage, and partial exposed wires. This is consistent with the results of our previous trial judgments. This is the lead wire diversion fault that is the closed loop formed at the contact point between the inner wall of the copper pipe of the casing and the lead cable, and generates heat and discharge when the load current flows. The actual scene is shown in figure 1 and figure 2 .

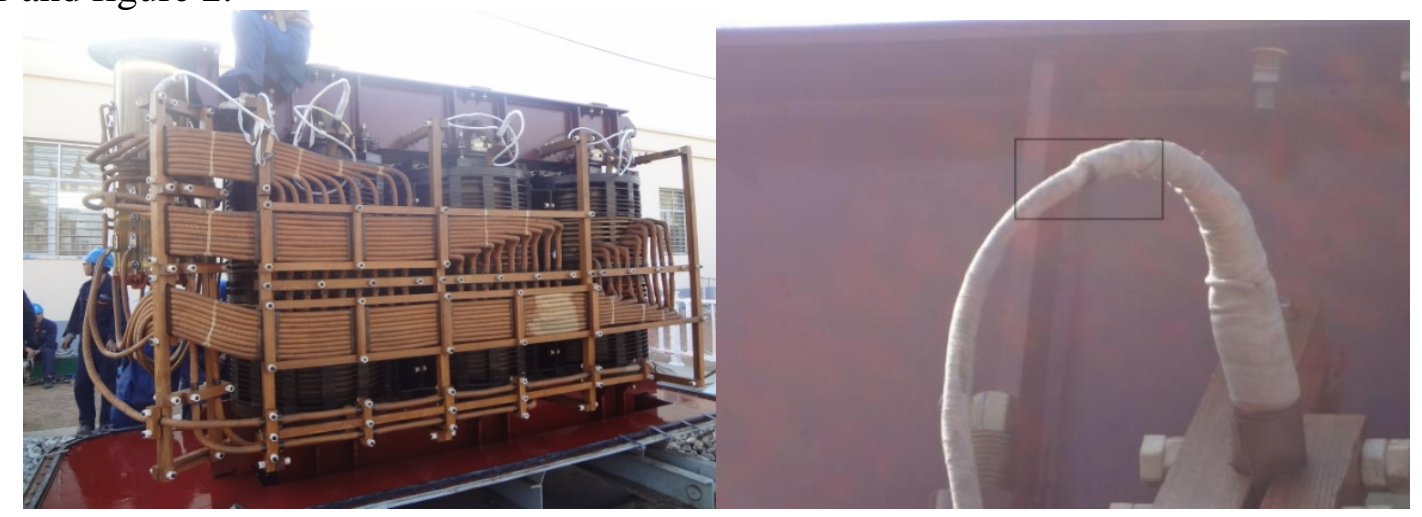

Fig.1

Fig.2 


\section{Conclusions}

In the process of finding internal transformer faults, transformer oil is sampled for data analysis that based on the analysis of insulating oil gas chromatography. Transformer overheating fault caused by conductive loop by using the three-ratio method and the four-ratio method combined with the transformer iron grounding current test method. Meanwhile ,the three possible causes of overheating that are poor contacting of tap-changer, Loose bolt of lead wire clips or poor welding of linker and short circuit in windings, broken strands, poor insulation between layers have been ruled out by conventional testing methods such as transformer insulation resistance, DC resistor, transformation ratio, dielectric loss and capacitance. The final judgment is that the lead wire diversion is the cause of the transformer overheating fault. Checking the location of the fault by inspecting core of the transformer, Fault type is judged to be consistent with previous analysis. Gas chromatographic analysis technology combined with traditional electrical test methods is fully demonstrated to determine the accuracy and scientificity of transformer internal faults in working. This is an effective method and has the value of promotion and application. It is a great role in guiding the transformer fault diagnosis on the spot for electrical tester on-site judgment in the future.

\section{References}

[1] Chen Huagang. Electric power equipment abnormal operation and accident handling manual. Water Conservancy and Electric Power Press. (2015.03)

[2] Cao Dunkui. Gas analysis and fault inspection in transformer oil. Beijing: China Electric Power Press (2003.03)

[3] Yin Kening. Transformer design principle. Beijing: China Electric Power Press (2003)

[4] Miao Shihong, Zhu Yongli. Power plant electrical part. China Electric Power Press (2015.08)

[5] Zhao Zhida. High voltage technology. China Electric Power Press (2013.05) 